Article

\title{
Monitoring, Human Health Risk Assessment and Optimized Management for Typical Pollutants in Indoor Air from Random Families of University Staff, Wuhan City, China
}

\author{
Xiyao Chen ${ }^{1,2}$, Fei Li ${ }^{1,2, *}$, Chaoyang Liu ${ }^{1,2, *}$, Jun Yang ${ }^{1,2}$, Jingdong Zhang ${ }^{1,2}$ and \\ Chunlin Peng ${ }^{3}$ \\ 1 Research Center for Environment and Health, Zhongnan University of Economics and Law, Wuhan 430073, \\ China; xiyaochen@zuel.edu.cn (X.C.); z0004221@zuel.edu.cn (J.Y.); jdzhang@zuel.edu.cn (J.Z.) \\ 2 School of Information and Safety Engineering, Zhongnan University of Economics and Law, \\ Wuhan 430073, China \\ 3 School of Statistics and Mathematics, Zhongnan University of Economics and Law, Wuhan 430073, China; \\ ChunLinPeng@zuel.edu.cn \\ * $\quad$ Correspondence: lifei@zuel.edu.cn (F.L.); lcy@zuel.edu.cn (C.L); Tel./Fax: +86-027-8838-5169 (F.L.)
}

Received: 15 May 2017; Accepted: 22 June 2017; Published: 26 June 2017

\begin{abstract}
In this study, 31 workers at a university were randomly selected for indoor environmental monitoring in Wuhan. Two indicators, formaldehyde and total volatile organic compounds (TVOC), and using 139 monitoring points, monitored the indoor environment (including home and workplace) as well as the interior space of the main furniture. This study carried out the environmental quality assessment for TVOC based on the $\mathrm{dB}$ index method and the health risk assessment of indoor formaldehyde for the university staff receptors and, then focused on health risk in home environment to carry out detailed environmental health management. The results showed that TVOC in the three types of home spaces exceeded about $80 \%$ of the national standard. The excessive formaldehyde ratios for kitchens $(79 \%)$, bedrooms $(77 \%)$ and living rooms $(74 \%)$ were calculated. Formaldehyde health risks all exceeded the United States Environmental Protection Agency, (USEPA) acceptable risk threshold. The formaldehyde concentrations in workplaces were about $0.03 \mathrm{mg} \cdot \mathrm{m}^{-3}$. While the risk contribution of the home environment to the total average health risk $(0.0014$, whether male and female) is about $96 \%$. For the adapted and unadapted persons, $90 \%$ and $55 \%$ of the monitoring points were located within the long-term tolerable range of TVOC decibel application, respectively. Long-term exposure to such an environment can lead to the Sick Building Syndrome (SBS). On the other hand, through comparison of the concentration of pollutants in the interior spaces of furniture and home spaces, it was determined tentatively that the pollutants were mainly concentrated in rarely used furniture. In summary, the air pollution in the studied homes of university staff was much serious than that in workplaces, which showed a need to manage TVOC and formaldehyde pollution by the three means: the purchase of green products, removal of internal pollution from furniture, and creating a good indoor volatile diffusion environment to create a healthy home environment.
\end{abstract}

Keywords: indoor air; formaldehyde; TVOC; health risk assessment; families

\section{Introduction}

On 25 October 2016, the CPC Central Committee, the State Council, issued a "Healthy China 2030" plan. The outline clearly put forward that "build and share, national health" is the strategic theme of building a healthy China, with the fundamental purpose of developing better national health. The plan emphasizes the implementation of comprehensive prevention and controlling strategies for 
chronic diseases, to promote the integration of chronic disease prevention and control services within the home and to extensively carry out the construction of healthy homes. Home indoor air quality relates to human health, and research has shown that indoor airborne organic pollutants can induce a variety of diseases that endanger human health, the most globally-recognized of which are TVOC and formaldehyde [1].

Indoor volatile organic compounds (VOCs) have a wide variety of sources and include various internationally-certified carcinogens with multi-target cell physiological toxicity possibilities. For example, formaldehyde was identified as the first carcinogen in 2004 by the International Cancer Research Center (IARC) [2], and studies have shown that long-term exposure to low-dose formaldehyde $\left(0.017 \mathrm{mg} \cdot \mathrm{m}^{-3}-0.0678 \mathrm{mg} \cdot \mathrm{m}^{-3}\right)$ could reduce immunity, destroy nerve and genetic material, induce Leukemia, colon cancer, nasopharyngeal carcinoma, gastric cancer, and other malignant diseases. At the same time, a certain concentration of total volatile organic compounds (TVOC) will give a clear sense of skin and mucous membrane irritation, leading to Sick Building Syndrome (SBS), which can cause headaches, fatigue, difficulty breathing, drowsiness, and other adverse symptoms. Studies have shown that TVOC will make blood eosinophil counts rise significantly, causing asthma, and a rise in benzene content will increase the incidence of bronchitis in children, resulting in the associated chronic toxic encephalopathy [3].

At present, the study of indoor air quality is mainly carried out from two perspectives, namely evaluation and management. Air quality evaluation of indoor microenvironments primarily includes formaldehyde and TVOC as the monitoring indexes. The former has high health risk, while the latter directly affects the ability of a person to breathe. The study site covers the dormitories [4], classrooms [5], offices [5,6], academic institutes [7-9], shopping malls [10-12], hotels, photocopy centers [13], guesthouses, entertainment places, and other types of spaces [14-16]. From the research point of view, in the relevant literature, in China, the acceptable risk threshold references the USEPA's standard of $1.00 \times 10^{-6}$. It was frequently found that nearly $100 \%$ of samples exceeded the USEPA standard. For example, in Guiyang City, 110 samples of formaldehyde all exceeded standards [5], as did samples from Xuzhou City and 56 university dormitory samples [4]. Studies also have different views on exposure concentrations in health risk assessments. Due to the relative concentration of university staff residences, it was relatively simple to control the differences attributed to the outdoor environment; in addition, the lifestyles of the university staff were relatively regular and the time of exposure was easy to monitor. The university staffs were selected to carry out the research. And their indoor environment was defined as home and workplace environment.

The objectives of this paper are: (i) to monitor TVOC and formaldehyde in Wuhan university workers' living rooms, bedrooms, and kitchens, using the $\mathrm{dB}$ index method proposed for indoor TVOC evaluation; (ii) to evaluate the health risk of formaldehyde in different indoor environments including home and workplace based on the previous studies and our exposure parameters survey; (iii) to investigate the concentration of pollutants in the interior space of furniture, combining room characteristics and the concentration of pollutants in order to identify the initial pollution source; and (iv) to carry out an error analysis and explore the compatibility between the various methods, according to the environmental quality standards of multiple countries, indoor air quality assessment methods, and related research on health risk assessments.

\section{Materials and Methods}

\subsection{Study Area}

According to previous surveys, outdoor concentrations of formaldehyde are very low and almost impossible to measure. In this study, the indoor environment includes the home and workplace environments. Therefore, a total of 139 monitoring points were set up in 31 homes (including 39 bedrooms, 31 living rooms, and 29 kitchens) and 40 workplaces. Monitoring points were required to be kept in place for two years. Most important, the three types of spaces needed to have doors and 
windows to create relatively-closed environments; otherwise they were treated as a sampling point. In order to determine the source of pollutants, the internal space of furniture that was normally used, without any special treatment, was to be monitored.

\subsection{Collection of Samples}

This study was conducted in accordance with the method specified in the Technical Specification for Indoor Ambient Air Quality Monitoring (HJ/T 167-2004). According to the size of the indoor areas, and the field situation, the quantity of sampling sites was determined, to correctly reflect the degree of indoor air pollutants. Since the area was less than $50 \mathrm{~m}^{2}$, only 1 to 3 sampling points were needed; thus, three sampling points were set in the living room, distributed on the diagonal, and the average value of the three points represented the pollution level. The rest of the rooms were relatively small, only needing a single sampling point, located in the middle of the room. All points were more than $0.5 \mathrm{~m}$ away from the walls, and more than $1 \mathrm{~m}$ away from doors and windows. The height of the sampling points was chest height, consistent with the human respiratory belt. In the case of furniture in the original state without special treatment, the interior spaces of the furniture were to be monitored for formaldehyde and TVOC concentrations.

In this study, the formaldehyde concentration was determined using the PGM-6208 Portable Formaldehyde Analyzer (manufactured by Huarui, Corona, CA, USA) and using the PGM-7340 Type portable volatile organic compounds (VOCs) analyzer (US Huarui) to determine the TVOC concentration. The PGM-6208 has been calibrated regularly by the instrument agent. Using $1 \mu \mathrm{mol} \cdot \mathrm{mol}^{-1}$ of standard carbon monoxide gas for calibration, the error of indication was within $5 \%$ FS. The PGM-7340 is calibrated with a standard sample of butylene by Hubei Institute of Measurement and Testing Technology, and the calibration results showed the recovery of standard addition was $98.20-101.76 \%$, the relative standard deviation was below $3.00 \%$. When using PGM-6208, the instrument had to be calibrated with fresh air, after the self-test was completed.

\subsection{Assessment Methodology}

\subsubsection{DB index Method}

TVOC is sensed by means of olfactory (smell) sensors, the impact of which depends on the magnitude of the stimulus $[17,18]$. According to the Yaglou theory and the Weber/Fechner theorem, Jokl M.V. from the Czech University of Prague defined the $L_{\text {odor(TVOC) }}$ as TVOC evaluation index using the decibel concept. The Jokl application decibel evaluation model is used to characterize a linear relationship between TVOC monitored concentration and Predicted Dissatisfaction of Air Quality (PDA).

On the Psycho-Physical Scale according to Yaglou, the minimum threshold is 1 when the $50 \mu \mathrm{g} \cdot \mathrm{m}^{-3}$, at the meaning time, the PDA $=5.8 \%[19]$, TVOC decibels are represented by " $d T v^{\prime \prime}$ or "decitvoc". It is computed through the following the equation [20]:

$$
L_{\text {odor }(T V O C)}=50 \log \left(\frac{C_{i}}{C_{0}}\right) \quad[d T v]
$$

where $d T v$ (decibel TVOC) is a new decibel unit for odor level caused by TVOC from building materials and other sources; $C_{i}$ is the monitored concentration of TVOC, $\mu \mathrm{g} \cdot \mathrm{m}^{-3} ; C_{1}$ is $50 \mu \mathrm{g} \cdot \mathrm{m}^{-3}$ based on the TVOC concentration when the minimum smell threshold of healthy human body in the Yaglou theory $[17,20]$.

TVOC concentration in the model used by the study was measured by a flame ionization detector calibrated against toluene [21]. Although the flame ionization detector has a high sensitivity, its volume and weight are very large, and it cannot be carried to the detection site, and so is not convenient for the large number of scattered market demands for personal detection services. The instrument PGM-7340 used in this study uses photoionization detection (PID), without pretreatment, is easy to carry, 
can analyze the multi-component low concentration quickly and, more importantly, the sensitivity is nearly 2 orders of magnitude higher than the flame ionization detector (FID). This method is based on the original PID. As a new rapid detection method, it is widely used in the analysis of non-arbitration classes. Meanwhile, with the high application value, it has also been approved by the national standard (HJ/T 167-2004) as the recommended method for TVOC. According to the national standard, the FID method and PID method both can be used for indoor environmental quality evaluation, but because of the definition of TVOC, the values of TVOC are different to a certain extent, and the quotients of them are between 1.5 and 3.5 [22].

\subsubsection{Health Risk Assessment}

This study used the United States Environmental Protection Agency (USEPA) health risk assessment model [23,24], while referring to the Ministry of Environmental Protection and the Chinese environmental exposure behavior research report. Since indoor air pollutants are mainly ingested through the respiratory tract, intake via skin and the digestive system can be ignored [25]; the health risk can be computed through the following equation:

$$
\text { Health Risk }=C \times E I \times S F
$$

where Health Risk in the equation is dimensionless; $C$ is the concentration of pollutants, $\mathrm{mg} \cdot \mathrm{m}^{-3}$; $E I$ is the exposure coefficient, $\mathrm{m}^{3} \cdot \mathrm{kg}^{-1} \cdot \mathrm{day}^{-1}$; $S F$ is the carcinogenic slope factor, $\mathrm{kg} \cdot \mathrm{day} \cdot \mathrm{mg}^{-1}$.

The $S F[26]$ and $E I$ formulas are shown as Equations (3) and (4), respectively:

$$
S F=\frac{U R F \times B W \times C F}{I R \times A R}
$$

where $U R F$ is the unit risk factor, $\mathrm{m}^{3} \cdot \mathrm{g}^{-1} ; A R$ is the absorption rate, except in special circumstances, usually taking a value of $1 ; B W$ is adult weight, $\mathrm{kg}$; $C F$ is the unit conversion factor $\left(1000 \mathrm{~g} \cdot \mathrm{mg}^{-1}\right)$; and $I R$ is respiratory rate, $\mathrm{m}^{3} \cdot \mathrm{day}^{-1}$.

$$
E I=\frac{I R}{B W} \times \frac{E T}{A T}
$$

where $B W$ is adult weight, $\mathrm{kg} ; \mathrm{IR}$ is the respiratory rate, $\mathrm{m}^{3} \cdot$ day $^{-1} ; E T$ is the exposure time, $\mathrm{h}$; AT is the total time, $24 \mathrm{~h}$ [27-30].

\section{Results and Discussion}

\subsection{Indoor Environmental Quality Evaluation for Typical Pollutants from the Random Families of University Staff}

According to the "indoor air quality standards" (GB/T 18883-2002) (hereafter referred to as the standard), the limited concentration of formaldehyde and TVOC in the air were $0.10 \mathrm{mg} \cdot \mathrm{m}^{-3}$ and $0.60 \mathrm{mg} \cdot \mathrm{m}^{-3}$, respectively. The overall situation at the university was as follows: Firstly, about $80 \%$ of the monitoring points for formaldehyde and TVOC exceeded the standard. Second, the revealed ratios of formaldehyde were in the following order: Kitchen $(79 \%)>$ bedroom $(77 \%)>$ living room (74\%). Third, the revealed ratios of TVOC of the living room, bedroom, and kitchen were $81 \%$, $79 \%$, and $78 \%$, respectively. In order to test whether the data came from the same distribution, the Kolmogorov-Smirnov test, which is a non-parametric test and independent of the distribution hypothesis, was adopted for the two samples. $\mathrm{H}_{0}$ : The data of the two samples were subject to the same distribution. $\mathrm{H}_{1}$ : The data of both samples were not from the same distribution. If the $p$ value was less than 0.05 , the original hypothesis could be rejected, otherwise the original hypothesis needed to be accepted, and the two-sample data were subjected to the same distribution. The $p$ values, as shown in Table 1, demonstrated no significant statistical difference $(p>0.05)$ and all concentration series of the same pollutant were from the same distribution. But the environmental temperature, 
humidity, ventilation, illumination, and other factors, in the three types of spaces had a certain degree of representativeness, all of which may affect formaldehyde volatilization [31].

Table 1. Significant difference test results.

\begin{tabular}{ccc}
\hline$p$ Value & Formaldehyde & TVOC \\
\hline Bedroom, living room & 0.33 & 0.58 \\
Bedroom, kitchen & 0.75 & 0.94 \\
Living room, kitchen & 0.13 & 0.83 \\
\hline
\end{tabular}

As shown in Table 2, the value range of pollutant concentrations was large, and the standard deviation was higher, which was mainly due to the individuality of the sampling points. The median was chosen to represent the level of formaldehyde, which was determined to be: Kitchens $\left(0.16 \mathrm{mg} \cdot \mathrm{m}^{-3}\right)$ $>$ bedrooms $\left(0.15 \mathrm{mg} \cdot \mathrm{m}^{-3}\right)>$ living rooms $\left(0.13 \mathrm{mg} \cdot \mathrm{m}^{-3}\right)$. The concentrations of TVOC generally exceeded that of the standard by 2 or 3 times. Furthermore, the bedroom pollution was relatively more serious than the other places pollution.

Table 2. Pollutant concentrations $\left(\mathrm{mg} \cdot \mathrm{m}^{-3}\right)$ for the three spaces.

\begin{tabular}{ccccccc}
\hline & \multicolumn{2}{c}{ Bedroom } & \multicolumn{2}{c}{ Living Room } & \multicolumn{2}{c}{ Kitchen } \\
\cline { 2 - 7 } & HCHO & TVOC & HCHO & TVOC & HCHO & TVOC \\
\hline Average & 0.17 & 1.39 & 0.14 & 1.33 & 0.18 & 1.25 \\
Minimum & 0.02 & 0.21 & 0.02 & 0.29 & 0.02 & 0.39 \\
Maximum & 0.53 & 6.81 & 0.37 & 3.06 & 0.38 & 3.95 \\
Standard deviation & 0.12 & 1.18 & 0.09 & 0.67 & 0.09 & 0.73 \\
Median & 0.15 & 1.27 & 0.13 & 1.27 & 0.16 & 1.21 \\
\hline
\end{tabular}

The results of the $\mathrm{dB}$ index method were relatively clear, as shown in Table 3 . The results showed $84.6 \%$ of the bedrooms, $93.5 \%$ of the living rooms and $96.5 \%$ of the kitchens were located within the long-term tolerable concentration range that was deemed as unsuitable for people. Regarding adapted persons, the evaluation results were somewhat better: $61.2 \%$ in the living rooms, $53.8 \%$ in the bedrooms, and $51.7 \%$ in the kitchens, which were within the long-term allowable concentration range. In a long-term situation, percentage dissatisfaction (PDA) would only be $20-30 \%$, and the probability of the Sick Building Syndrome would be higher, which could cause adverse reactions, such as fatigue, drowsiness, headache, dyspnea, irritation of the respiratory tract mucosa, and asthma. In addition, for people with respiratory diseases, the "decitvoc" values should be controlled to within $30 \mathrm{~dB}$. If TVOC is determined by flame ionization method, the evaluation result may float up and down within one evaluation interval. In fact, the basis of the evaluation method was mainly settled by Molhave. In view of the research findings of Molhave in 1991, PID is a new method developed in the last 20 years as a fast detection method with very high accuracy in terms of ppm level, and no selectivity. It seems to be more consistent with the original hypothesis of Molhave [17]. However, the studies for the concept, detection and evaluation of TVOC are still not perfect, and need further research. 
Table 3. DB index method; scope and results.

\begin{tabular}{|c|c|c|c|c|c|c|}
\hline Range & Name & $\begin{array}{l}\text { Concentration } \\
\left(\mu \mathrm{g} \cdot \mathrm{m}^{-3}\right)\end{array}$ & $\begin{array}{l}\text { Decibel } \\
\text { (dB) }\end{array}$ & Bedroom & $\begin{array}{l}\text { Living } \\
\text { Room }\end{array}$ & Kitchen \\
\hline \multirow{7}{*}{$\begin{array}{c}\text { Ranges } \\
\text { unadapted }\end{array}$} & Optimal range & 50-200 & $0-30$ & 1 & 0 & 0 \\
\hline & Asthmatic optimal range & $50-85$ & $0-12$ & 0 & 0 & 0 \\
\hline & Asthmatic admissible range & $86-200$ & $13-30$ & 1 & 0 & 0 \\
\hline & Admissible range & $201-360$ & $31-43$ & 3 & 2 & 0 \\
\hline & Long-term tolerable (SBS) range & $361-3000$ & $44-89$ & 33 & 29 & 28 \\
\hline & Short-term tolerable range & $3001-25,000$ & $90-135$ & 3 & 0 & 1 \\
\hline & Intolerable range & $>25,001$ & $>136$ & 0 & 0 & 0 \\
\hline \multirow{7}{*}{$\begin{array}{l}\text { Ranges } \\
\text { adapted }\end{array}$} & Optimal range & $50-580$ & $0-53$ & 8 & 5 & 6 \\
\hline & Asthmatic optimal range & $50-250$ & $0-35$ & 2 & 0 & 0 \\
\hline & Asthmatic admissible range & $251-580$ & $36-53$ & 6 & 5 & 6 \\
\hline & Admissible range & $581-1040$ & $54-66$ & 9 & 7 & 8 \\
\hline & Long-term tolerable (SBS) range & $1041-3000$ & $67-89$ & 21 & 19 & 15 \\
\hline & Short-term tolerable range & $3001-25,000$ & $90-135$ & 3 & 0 & 1 \\
\hline & Intolerable range & $>25,001$ & $>136$ & 0 & 0 & 0 \\
\hline
\end{tabular}

\subsection{Health Risk Assessment}

Considering the nature of unit risk, the health risk (probability) is a result of long-time exposure to chemicals throughout one's life. In order to more completely show the indoor exposure to health risks of the studied staff, the study specifically set up 40 workplaces to calculate the health risks. The 40 workplaces included 24 classrooms and 16 offices or duty rooms. The average of the formaldehyde concentrations in these workplaces was about $0.03 \mathrm{mg} \cdot \mathrm{m}^{-3}$, which may be because the university adopted a centralized office form and the decoration materials were mainly aluminum alloy and organic glass.

The USEPA IRIS system's URF value of formaldehyde is $0.000013 \mathrm{~m}^{3} \cdot \mathrm{g}^{-1}$. According to our research, the weight of adult males and adult females were $72.8 \mathrm{~kg}$ and $56.2 \mathrm{~kg}$, respectively, and referring to a report on the behavior patterns of Chinese people's environmental exposure (volume) the respiratory rate of adult males and adult females were given as $18 \mathrm{~m}^{3} \cdot \mathrm{day}^{-1}$ and $14.5 \mathrm{~m}^{3} \cdot \mathrm{day}^{-1}$, respectively. Therefore, Chinese adult male carcinogenic slope factor was $0.053 \mathrm{~kg} \cdot \mathrm{day} \cdot \mathrm{mg}^{-1}$, and that of a female was $0.050 \mathrm{~kg} \cdot \mathrm{day} \cdot \mathrm{mg}^{-1}$. Exposure times are shown in Tables 4 and 5.

Table 4. Time allocation and exposure coefficients of female workers.

\begin{tabular}{|c|c|c|c|c|}
\hline \multirow[b]{2}{*}{ Environment } & \multicolumn{3}{|c|}{ Daily Exposure Time } & \multirow{2}{*}{$\begin{array}{l}\text { EI, Exposure Coefficien } \\
\left(\mathrm{m}^{3} \cdot \mathrm{kg}^{-1} \cdot \mathrm{day}^{-1}\right)\end{array}$} \\
\hline & Working Day (h) & Off Day (h) & $\begin{array}{l}\text { Annual Daily } \\
\text { Average (h) }\end{array}$ & \\
\hline Living room & 5.01 & 5.28 & 5.14 & 0.06 \\
\hline Bedroom & 7.11 & 7.00 & 7.06 & 0.08 \\
\hline Kitchen & 2.25 & 2.92 & 2.56 & 0.03 \\
\hline Workplace & 6.38 & 0.00 & 3.50 & 0.04 \\
\hline
\end{tabular}

Table 5. Time allocation and exposure coefficient of male workers.

\begin{tabular}{ccccc}
\hline \multirow{2}{*}{ Environment } & \multicolumn{3}{c}{ Male Workers Daily Exposure Time } & EI, Exposure Coefficient \\
\cline { 2 - 4 } & Working Day (h) & Off Day (h) & $\begin{array}{c}\text { Annual Daily } \\
\text { Average (h) }\end{array}$ & $\begin{array}{c}\mathbf{k g}^{\mathbf{1}} \cdot \mathbf{d a y}^{\mathbf{- 1}} \mathbf{)} \\
\text { Living room }\end{array}$ \\
Bedroom & 5.64 & 5.67 & 5.65 & 0.06 \\
Kitchen & 7.02 & 7.20 & 7.11 & 0.07 \\
Workplace & 1.42 & 2.66 & 2.00 & 0.02 \\
\hline
\end{tabular}


It can be concluded that the health risk of formaldehyde was mainly determined by exposure time and exposure concentration, calculated using Equations (2)-(4). As shown in Tables 4 and 5, the annual daily average of the exposure time was in the following order: Bedrooms $>$ living rooms $>$ workplaces $>$ kitchens. The exposure time of adult females was significantly more than that of adult males, which was related to Chinese living habits. Therefore, women should be more aware of environmental pollution in the kitchen.

As shown in Table 6, the health risks all exceeded the acceptable USEPA risk threshold $\left(1.00 \times 10^{-6}\right)$. The total average health risks for males and females were all about 0.0014 . The contribution of the home environment to the overall average health risk is about $96 \%$. Therefore, this study carried on the specific research and analysis of the home environment. The average health risks of formaldehyde were in the following order: Bedrooms $>$ living rooms $>$ kitchens $>$ workplaces.

Table 6. Health risks of formaldehyde in different environments.

\begin{tabular}{|c|c|c|c|c|c|c|c|c|c|}
\hline & & \multicolumn{2}{|c|}{ Bedroom } & \multicolumn{2}{|c|}{ Living room } & \multicolumn{2}{|c|}{ Kitchen } & \multicolumn{2}{|c|}{ Workplace } \\
\hline & & Male & Female & Male & Female & Male & Female & Male & Female \\
\hline \multicolumn{2}{|c|}{ Average $\left(\times 10^{-5}\right)$} & 68.3 & 73.84 & 43.66 & 39.67 & 19.3 & 24.75 & 5.62 & 5.72 \\
\hline \multicolumn{2}{|c|}{$\operatorname{Minimum}\left(\times 10^{-5}\right)$} & 7.7 & 8.32 & 6.12 & 5.57 & 2.18 & 2.77 & 1.41 & 1.43 \\
\hline \multicolumn{2}{|c|}{ Maximum $\left(\times 10^{-5}\right)$} & 204.02 & 220.56 & 113.31 & 102.95 & 41.15 & 52.77 & 13.1 & 13.3 \\
\hline \multirow{3}{*}{$\begin{array}{l}\text { Percentage of } \\
\text { risk thresholds } \\
\text { exceeded }\end{array}$} & $10^{-4}$ & $94.90 \%$ & $94.90 \%$ & $90.30 \%$ & $90.30 \%$ & $6.90 \%$ & $43.40 \%$ & $0.00 \%$ & $0.00 \%$ \\
\hline & $10^{-5}$ & $100 \%$ & $100 \%$ & $100 \%$ & $100 \%$ & $96.60 \%$ & $100 \%$ & $100 \%$ & $100 \%$ \\
\hline & $10^{-6}$ & $100 \%$ & $100 \%$ & $100 \%$ & $100 \%$ & $100 \%$ & $100 \%$ & $100 \%$ & $100 \%$ \\
\hline
\end{tabular}

Generally speaking, the pollution in the three kinds of spaces were caused by different pollution sources and environmental factors. The micro-environment in the kitchen space was that they were small, quite damp, and had poor ventilation. Pollutant sources included smoke, gas, chemicals (such as detergents, pesticides, etc.), and volatile gas from decorative materials, as well as biological metabolic gases [32]. Comparing the bedrooms and living rooms, the bedroom environments were higher in temperature and had a large number of decorations, with furniture and furnishings. In addition, there were a number of leather materials, home textiles, clothing, artificial boards, soft packages, cosmetics, and other pharmacy and hygiene items [33], all of which resulted in a large amount of volatile organic pollutants. The temperature and humidity were suitable for the growth of mites, bacteria, and other microorganisms. Mildew, corruption, and other microbial metabolisms facilitated the volatilization of contaminants from materials. Compared to the bedrooms and kitchens, the living rooms were larger, better ventilated, and much brighter. The main pollutants were from the TV cabinet, sofa, wallpaper, wall paint, and other furniture materials [34-36].

There were some systematic errors in the abovementioned health risk assessments, which were mainly reflected in the concentrations of pollutants. At present, the indoor formaldehyde health risk assessment of a large sample is usually in accordance with the "indoor air quality monitoring technology standard" (HJ/T 167-2004). The concentration of pollutants in rooms that were closed for $12 \mathrm{~h}$ was used to replace the exposure concentration, but there were some differences between them. There was a system error between the risk and true values [37] due to the adopted national standard of $12 \mathrm{~h}$ as the "close time". On the other hand, domestic researchers generally adopt the acceptable safety threshold $\left(10^{-6}\right)$ from the U.S. Environmental Protection Agency. There are different security thresholds, from $1.00 \times 10^{-6}$ to $1.00 \times 10^{-4}$, which have some influence on the evaluation results, as shown in Table 6 . The concentration limits of formaldehyde, calculated using different security thresholds, also have certain differences, ranging from $10^{-4}$ to $10^{-1} \mathrm{mg} \cdot \mathrm{m}^{-3}$. This also shows that there is a certain degree of compatibility between indoor air quality evaluation and health evaluations. It is important for China to study health risk assessments of indoor pollutants further. 


\subsection{Discussion on Evaluation Method of Indoor Pollutants Classification}

At present, China's current standards of "indoor air quality standards" (GB/T 18883-2002) refer to legislation in Australia, Canada, America and seven other countries and regions, in trials of indoor air qualities for residential and office buildings. Through investigation, the domestic and foreign standards are compared as follows: National standards for formaldehyde and TVOC are limited to $0.1 \mathrm{mg} \cdot \mathrm{m}^{-3}$ and $0.6 \mathrm{mg} \cdot \mathrm{m}^{-3}$, respectively; WHO limits formaldehyde to $0.1 \mathrm{mg} \cdot \mathrm{m}^{-3}$. Formaldehyde and TVOC in Japan are limited to 0.1 and $0.4 \mathrm{mg} \cdot \mathrm{m}^{-3}$, respectively. The formaldehyde standard in Norway is $0.06 \mathrm{mg} \cdot \mathrm{m}^{-3}$; formaldehyde cannot exceed $0.123 \mathrm{mg} \cdot \mathrm{m}^{-3}$ in Canada. In general, the limited concentration of formaldehyde is about $0.1 \mathrm{mg} \cdot \mathrm{m}^{-3}$, but the monitoring time range is different; the values of $1 \mathrm{~h}, 0.5 \mathrm{~h}, 24 \mathrm{~h}$, and $1 \mathrm{~h}$ (on average) are for China, WHO, Japan, and Canada, respectively [38]. Indoor air quality standard evaluation methods are easy to measure air quality, but cannot directly reflect the relationship between the concentrations of pollutants and harm to the human body [39]. Comparison of national standard methods requires professionals to interpret data, and the evaluation results are affected by subjective factors and professional experience. Therefore, indoor air quality standard evaluation methods cannot meet the current needs of residents.

Based on previous literature regarding the concentration of formaldehyde-human body reactions, formaldehyde concentration is divided into the following sections, according to the reaction of formaldehyde inhalation, as shown in Table 7. According to relevant interviews and investigations, TVOC and formaldehyde concentrations were chosen as the evaluation indices of indoor environmental quality, and a rough classification evaluation scheme, combining air quality and pollution control, was put forward (Table 8).

Table 7. Formaldehyde concentration-response relationship.

\begin{tabular}{cc}
\hline Formaldehyde Concentration $\left.\mathbf{( m g} \cdot \mathbf{m}^{-3}\right)$ & Body Reaction \\
\hline 0.05 & EEG changes \\
0.06 & Irritating smell \\
0.07 & Children with mild asthma \\
0.10 & Smell and discomfort \\
0.12 & Upper respiratory tract irritation threshold \\
0.45 & Increased respiratory disease \\
0.50 & Irritating eyes, causing tears \\
\hline
\end{tabular}

Table 8. Grading evaluation scheme.

\begin{tabular}{|c|c|c|c|}
\hline $\begin{array}{c}\text { Formaldehyde } \\
\text { Woncentration, } \mathrm{mg} \cdot \mathrm{m}^{-3}\end{array}$ & TVOC Decibel Value, dB & Protection Class & Comments \\
\hline$\leq 0.05$ & $\leq 30$ & A & Clean \\
\hline$\leq 0.1$ & $\leq 54$ & $\mathrm{~B}$ & Not polluted \\
\hline$\leq 0.1$ & $\leq 67$ & $\mathrm{C}$ & Light pollution \\
\hline$\leq 0.2$ & $\leq 54$ & $\mathrm{D}$ & Moderate pollution \\
\hline \multicolumn{2}{|c|}{ Other areas } & $\mathrm{E}$ & Severe pollution \\
\hline
\end{tabular}

With a formaldehyde concentration of $0.05 \mathrm{mg} \cdot \mathrm{m}^{-3}$, human brain waves begin to appear abnormal; at $0.10 \mathrm{mg} \cdot \mathrm{m}^{-3}$, the national standard value, the body begins to perceive the smell and feel uncomfortable; at $0.20 \mathrm{mg} \cdot \mathrm{m}^{-3}$, the body begins to produce strong olfactory stimuli, and the eyes, nose, throat and upper respiratory tract are heavily irritated [40].

Decitvoc: $30 \mathrm{~dB}$, a concentration of about $0.2 \mathrm{mg} \cdot \mathrm{m}^{-3}$ is the allowable limited concentration for adapted persons, while asthma patients may feel uncomfortable [41]; $54 \mathrm{~dB}$, a concentration of about $0.6 \mathrm{mg} \cdot \mathrm{m}^{-3}$, is the national TVOC standard and the allowable limit concentration for asthma patients in adapted persons; $67 \mathrm{~dB}$, a concentration of about $1.04 \mathrm{mg} \cdot \mathrm{m}^{-3}$, is the long term tolerable range for adapted persons, when $30 \%$ of people have difficulty breathing $(\mathrm{PDA}=30 \%)$. 
In the abovementioned classification program, Level A is clean. Level B does not exceed the national standard, but normal ventilation needs to be protected by place green plants and improving indoor air quality. Level C is slight pollution, where the main pollutants are TVOC. Level D is polluted, where the main pollutant is formaldehyde. Level $C$ and Level D need to identify the source of pollution, focusing on the main source for pollution control. Level E needs all-around comprehensive management, focusing on decoration materials the pollution source control, supplemented by an activated carbon package and photo-catalysts to reduce the formaldehyde concentrations in the internal spaces of furniture.

\subsection{Analysis of Pollution Release Source}

With respect to furniture wood, as shown in Table 9, the organic pollution problem in the interior space of furniture was very prominent. It can be seen from the table that the concentration of pollutants in the interior of the furniture was similar to that of the external environment, such as in wardrobes, TV cabinet drawers, and computer desk drawer [42,43]. Due to the accumulation of air pollution, the interior space of the less-used furniture becomes a potential repository of pollutants, such as atop bedroom cabinets, or cabinets and drawers near the ground, therefore, creating the possibility of short-term high concentrations of formaldehyde.

Table 9. Pollutant concentrations of the interior spaces of indoor furniture.

\begin{tabular}{|c|c|c|c|c|c|}
\hline Room & $\begin{array}{l}\text { Formaldehyde } \\
\text { Concentration } \\
\left(\mathrm{mg} \cdot \mathrm{m}^{-3}\right)\end{array}$ & $\begin{array}{c}\text { TVOC } \\
\left(\mathrm{mg} \cdot \mathrm{m}^{-3}\right)\end{array}$ & Furniture & $\begin{array}{c}\text { Formaldehyde } \\
\text { Concentration } \\
\left(\mathrm{mg} \cdot \mathrm{m}^{-3}\right)\end{array}$ & $\begin{array}{c}\text { TVOC } \\
\left(\mathrm{mg} \cdot \mathrm{m}^{-3}\right)\end{array}$ \\
\hline \multirow{3}{*}{1} & \multirow{3}{*}{0.28} & \multirow{3}{*}{0.876} & Top lockers & 2.6 & 6.000 \\
\hline & & & Bottom lockers & 1.37 & 25.18 \\
\hline & & & Central lockers & 0.98 & 6.376 \\
\hline \multirow{3}{*}{2} & \multirow{3}{*}{0.21} & \multirow{3}{*}{1.260} & Top lockers & 0.66 & 14.68 \\
\hline & & & Central lockers & 0.59 & 7.983 \\
\hline & & & Bottom lockers & 0.59 & 16.14 \\
\hline \multirow[b]{2}{*}{3} & \multirow{2}{*}{0.12} & \multirow{2}{*}{0.581} & Computer table drawers & 0.18 & 1.757 \\
\hline & & & Bookcases & 0.26 & 0.954 \\
\hline \multirow{2}{*}{4} & \multirow{2}{*}{0.47} & \multirow{2}{*}{1.207} & Wardrobes & 0.9 & 1.369 \\
\hline & & & Bedside cabinets & 1.18 & 2.005 \\
\hline \multirow{2}{*}{5} & \multirow{2}{*}{0.33} & \multirow{2}{*}{1.224} & Big closets & 0.37 & 1.239 \\
\hline & & & Shoeboxes & 0.29 & 1.196 \\
\hline \multirow{2}{*}{6} & \multirow{2}{*}{0.13} & \multirow{2}{*}{1.708} & TV cabinets & 0.15 & 1.67 \\
\hline & & & Cupboards & 0.16 & 1.582 \\
\hline \multirow{3}{*}{7} & \multirow{3}{*}{0.22} & \multirow{3}{*}{2.129} & Bookcases & 0.32 & 2.33 \\
\hline & & & Drawers & 0.31 & 2.127 \\
\hline & & & Large cabinets & 0.29 & 2.088 \\
\hline \multirow{7}{*}{8} & \multirow{7}{*}{0.02} & \multirow{7}{*}{1.274} & TV cabinets & 0.1 & 1.354 \\
\hline & & & Computer desk cabinets & 0.15 & 1.789 \\
\hline & & & Computer desk lower cabinets & 0.44 & 1.006 \\
\hline & & & Drawers below windowsills & 0.11 & 1.352 \\
\hline & & & Windows under cabinets & 0.06 & 1.184 \\
\hline & & & Big closets & 0.06 & 0.787 \\
\hline & & & Large wardrobe drawers & 0.28 & 1.557 \\
\hline \multirow{2}{*}{9} & \multirow{2}{*}{0.13} & \multirow{2}{*}{1.708} & TV cabinets & 0.15 & 1.67 \\
\hline & & & Cupboards & 0.16 & 1.582 \\
\hline \multirow{3}{*}{10} & \multirow{3}{*}{0.22} & \multirow{3}{*}{2.129} & Bookcases & 0.32 & 2.33 \\
\hline & & & Study drawers & 0.31 & 2.127 \\
\hline & & & Study wardrobes & 0.29 & 2.088 \\
\hline
\end{tabular}


In daily life, formaldehyde is used as a raw material and industrial resin to produce furniture, home textiles, and decoration materials [44]. For example, particleboard is made up of a variety of organic chemicals (adhesives, curing agents, waterproofing agents, and others) and dry wood chips, by mixing them and pressing them into boards [45]. There are three main sources of indoor formaldehyde: Firstly, free-formaldehyde in decorative volatile materials in rooms; second, during plate hot-pressing of manufactured-wood furniture, adhesives are incompletely stabilized, and other oxygenated organic compounds decompose. Third, the external environment, temperature, humidity, moisture, and microbial actions cause the release of stabilized formaldehyde from materials. According to the current national standard "of China's wood-based panel interior decoration materials and products in limited release formaldehyde" (GB 18580-2001), wood-based panels with high formaldehyde emissions need to be treated; however, it was found that the treatment could not completely solve the problem of organic pollution. In addition, some of the inside surfaces of furniture were not finished, and two plates were found to be bonded using adhesive, resulting in a high concentration of pollutant enrichment in the interior space of furniture. Although there is no systematic and quantitative research on the volatilization of pollutants in furniture interiors, preliminary conclusions could be drawn that there were three important means of preventing and controlling indoor organic pollution: The purchase of green products, to remove furniture interior pollution, and to create a good diffusion within indoor environments.

\section{Conclusions}

This study carried out the environmental quality assessment for TVOC based on the $\mathrm{dB}$ index method and the health risk assessment of indoor formaldehyde, with a university staff in Wuhan City as the exposed group, and focused on the home environment to carry out detailed environmental health management. The results showed that the indoor pollution situation for staff at the studied university was relatively serious, especially the pollution at home. The most probable concentrations of contaminants in the kitchens $\left(0.16 \mathrm{mg} \cdot \mathrm{m}^{-3} \mathrm{HCHO}, 1.25 \mathrm{mg} \cdot \mathrm{m}^{-3} \mathrm{TVOC}\right)$ and bedrooms $\left(0.15 \mathrm{mg} \cdot \mathrm{m}^{-3}\right.$ $\mathrm{HCHO}, 1.39 \mathrm{mg} \cdot \mathrm{m}^{-3}$ TVOC) were relatively higher than those in others. Based on the $\mathrm{dB}$ index method, $90 \%$ and $55 \%$ of the monitoring points were located within the long-term tolerable range of TVOC decibel application for the adapted and unadapted persons, respectively. This indicated that people with respiratory diseases should pay more attention to indoor TVOC pollution. Whether male or female, the total average health risks were about 0.0014 . The average formaldehyde in workplaces was $0.03 \mathrm{mg} \cdot \mathrm{m}^{-3}$ and the health risk was about $5.6 \times 10^{-5}$. Generally, the contribution of the home environment to the total average health risk was about $96 \%$. With long exposure time, the carcinogenic health risks in the bedrooms $\left(6.8 \times 10^{-4}\right.$ for male, $7.4 \times 10^{-4}$ for female $)$ and living rooms $\left(4.4 \times 10^{-4}\right.$ for male, $4.0 \times 10^{-4}$ for female) were all higher than the acceptable risk threshold. Through the exploration of pollution release sources, it showed that the usage of green products, the removal of interior furniture pollution and the creation of a good diffusion environment were the key to prevent and control indoor pollution. The time concentration variables and the selection of enrichment and exposure time factors mainly affect the whole process of indoor environmental evaluation. Furthermore, based on the found compatibility issues between the compliance assessments and the practical health risk assessments, a compatible grading evaluation and management scheme was developed for better private and public decision-making.

Acknowledgments: This study was financially supported by the National Natural Science Foundation of China (51578222, 61602518 and 71503268) and the Humanities and Social Science Project of Hubei Provincial Education Department (17Z017, 17G025).

Author Contributions: Fei Li organized this study and conducted study design, performed the statistical analysis and drafted the manuscript. Xiyao Chen contributed to study design, prepared datasets, performed the statistical analysis and drafted the manuscript. Chaoyang Liu and Yun Yang contributed to study design, interpretation of analysis, and revision of the manuscript. Chunlin Peng contributed to study design and datasets prepare. Jingdong Zhang and Fei Li contributed to datasets prepare and revision of the manuscript. All read and approved the final manuscript. 
Conflicts of Interest: The authors declare no conflict of interest.

\section{References}

1. World Health Organization (WHO). Guidelines for Indoor Air Quality Selected Pollutants. Available online: http:/ / www.euro.who.int/_data/assets/pdf_file/0009/128169/e94535.pdf (accessed on 16 June 2017).

2. International Agency for Research on Cancer (IARC). Monographs on the Evaluation of Carcinogenic Risks to Humans: Formaldehyde, 2-Butoxyethanol and 1-tert-Butoxypropan-2-ol. Available online: http:/ / www.ncbi.nlm.nih.gov/books/NBK326468/ (accessed on 16 June 2017).

3. Zhang, J.Y.; Zhang, F.; Li, H.B. Practical Technology of Indoor Environment Monitoring and Management, 1st ed.; Chemical Industry Press: Beijing, China, 2015.

4. Wang, Y.L.; Liu, B.; Xu, Z. Health risk assessment for formaldehyde pollution of college dormitory. Environ. Sci. Technol. 2010, 23, 52-54.

5. Li, T.T.; Cheng, Y.L.; Yan, M. Human health risk assessment of benzene and formaldehyde in different indoor environment in Guiyang city. J. Enviorn. Health 2008, 25, 757-759.

6. Huang, L.; Mo, J.; Sundell, J.; Fan, Z.; Zhang, Y. Health risk assessment of inhalation exposure to formaldehyde and benzene in newly remodeled buildings, Beijing. PLoS ONE 2013, 11, e79553. [CrossRef] [PubMed]

7. Pilidis, G.A.; Karakitsios, S.P.; Kassomenos, P.A.; Kazos, E.A.; Stalikas, C.D. Measurements of benzene and formaldehyde in a medium sized urban environment. Indoor/outdoor health risk implications on special population groups. Environ. Monit. Assess. 2009, 150, 285. [CrossRef] [PubMed]

8. Huang, J.; Li, F.; Zeng, G.M.; Huang, X.; Liu, W.; Wu, H.; Gu, Y.; Li, X.; He, X.; He, Y. Integrating hierarchical bioavailability and population distribution into potential eco-risk assessment of heavy metals in road dust: A case study in Xiandao District, Changsha city, China. Sci. Total Environ. 2016, 541, 969-976. [CrossRef] [PubMed]

9. Cavalcante, R.M.; Seyffert, B.H.; Montes D'Oca, M.G.; Nascimento, R.F.; Campelo, C.S.; Pinto, I.S.; Anjos, F.B.; Costa, A.H.R. Exposure assessment for formaldehyde and acetaldehyde in the workplace. Indoor Built Environ. 2005, 14, 165-172. [CrossRef]

10. Crump, D.; Squire, R.; Brown, V.; Yu, C.; Coward, S.; Aizlewood, C. Investigation of volatile organic compounds in the indoor air of school over one year period following refurbishment. In Proceedings of the 10th International Conference on Indoor Air Quality and Climate, Beijing, China, 6 January 2005; pp. $659-663$.

11. Yamashita, S.; Kume, K.; Horiike, T.; Honma, N.; Fusaya, M.; Amagai, T. Emission sources and their contribution to indoor air pollution by carbonyl compounds in a school and a residential building in Shizuoka, Japan. Indoor Built Environ. 2011, 21, 392-402. [CrossRef]

12. Xiong, J.; Zhang, P.; Huang, S.; Zhang, Y. Comprehensive influence of environmental factors on the emission rate of formaldehyde and VOCs in building materials: Correlation development and exposure assessment. Environ. Res. 2016, 151, 734-741. [CrossRef] [PubMed]

13. Lee, C.W.; Dai, Y.T.; Chien, C.H.; Hsu, D.J. Characteristics and health impacts of volatile organic compounds in photocopy centers. Environ. Res. 2006, 100, 139-149. [CrossRef] [PubMed]

14. Norbäck, D.; Hashim, J.H.; Hashim, Z.; Ali, F. Volatile organic compounds (VOC), formaldehyde and nitrogen dioxide $\left(\mathrm{NO}_{2}\right)$ in schools in Johor Bahru, Malaysia: Associations with rhinitis, ocular, throat and dermal symptoms, headache and fatigue. Sci. Total Environ. 2017, 592, 153-160. [CrossRef] [PubMed]

15. Zhu, X.; Liu, Y. Characterization and Risk assessment of exposure to volatile organic compounds in apartment buildings in Harbin, China. B. Environ. Contam. Tox. 2014, 92, 96-102. [CrossRef] [PubMed]

16. Rovira, J.; Roig, N.; Nadal, M.; Schuhmacher, M.; Domingo, J. Human health risks of formaldehyde indoor levels: An issue of concern. J. Environ. Sci. Health A 2016, 51, 357-363. [CrossRef] [PubMed]

17. Molhave, L. Volatile organic compounds, indoor air quality and health. Indoor Air 1991, 4, 357-376. [CrossRef]

18. Oseland, N.A.; Raw, G.J. Perceived air quality: Discussion on the new units. Building Serv. Eng. Res. Technol. 1993, 14, 137-141. [CrossRef]

19. Fanger, P.O.; Berg-Munch, B.; Clausen, G. Ventilation requirements for the control of body odor in spaces occupied by women. Environ. Int. 1986, 12, 195-199.

20. Parine, N. The use of odour in setting ventilation rates. Indoor Environ. 1994, 3, 87-95. [CrossRef] 
21. Jokl, M.V. Evaluation of indoor air quality using the decibel concept based on carbon dioxide and TVOC. Build Environ. 2000, 35, 677-697. [CrossRef]

22. Ma, T.; Fang, Z.; Guan, S.; Dan, D.Z.; Tan, H.P. Study on method of quick determination of indoor VOC using VOC detector. China Meas. Technol. 2007, 33, 29-33.

23. US Environmental Protection Agency (U.S. EPA). Risk Assessment Guidance for Superfund Volume I-Human Health Evaluation Manual (Part A). Available online: https://www.osti.gov/scitech/biblio/7037757 (accessed on 16 June 2017).

24. US Environmental Protection Agency (U.S. EPA). Exposure Factors Handbook. Available online: http:/ / www.epa.gov/ncea/efh/pdfs/efh-chapter05 (accessed on 16 June 2017).

25. China Ministry of Environmental Protection. Report of Environmental Exposure Related Activity Patterns Research of Chinese Population (Adult Volume). Available online: https://www.amazon.co. uk/Environmental-Expusure-Activity-Patterns-Population/dp/7511116191 (accessed on 16 June 2017).

26. US Department of Energy. RAIS: Risk Assessment Information System. Available online: https://hero.epa. gov/hero/index.cfm/reference/details/reference_id/ 624905 (accessed on 16 June 2017).

27. Li, F.; Zhang, J.D.; Jiang, W.; Liu, C.Y.; Zhang, Z.M.; Zhang, C.D.; Zeng, G.M. Spatial health risk assessment and hierarchical risk management for mercury in soils from a typical contaminated site, China. Environ. Geochem. Health 2016. [CrossRef] [PubMed]

28. Li, F.; Zhang, J.D.; Yang, J.; Liu, C.Y.; Zeng, G.M. Site-specific risk assessment and integrated management decision-making: A case study of a typical heavy metal contaminated site, middle China. Hum. Ecol. Risk. Assess. 2016, 22, 1224-1241. [CrossRef]

29. Li, F.; Zhang, J.D.; Huang, J.H.; Huang, D.W.; Yang, J.; Song, Y.W.; Zeng, G.M. Heavy metals in road dust from Xiandao district, Changsha city, China: Characteristics, health risk assessment, and integrated source identification. Environ. Sci. Pollut. Res. 2016, 23, 13100-13113. [CrossRef] [PubMed]

30. Li, F.; Huang, J.H.; Zeng, G.M.; Huang, X.L.; Liu, W.C.; Wu, H.P.; Yuan, Y.J.; He, X.X.; Lai, M.Y. Spatial distributions and health risk assessment of heavy metals associated with receptor population density in street dust: A case study of Xiandao District, Middle China. Environ. Sci. Pollut. Res. 2015, 22, 6732-6742. [CrossRef] [PubMed]

31. Haghighat, F.; Bellis, L. Material emission rates: Literature review and the impact of indoor air temperature and relative humidity. Build. Environ. 1998, 33, 261-277. [CrossRef]

32. Sofuoglu, S.; Aslan, G.; Inal, F.; Sofuoglu, A. An assessment of indoor air concentrations and health risks of volatile organic compounds in three primary schools. Int. J. Hyg. Environ. Health 2011, 214, 36-46. [CrossRef] [PubMed]

33. Costa, S.; Costa, C.; García-Léston, J.; Coelho, P.; Silva, S.; Carvalho, S.; Laffon, B.; Porto, B.; Teixeira, J.P. Human exposure to formaldehyde, a risk evaluation of occupational health effects. Toxicol. Lett. 2014, 229, S116. [CrossRef]

34. Madureira, J.; Paciência, I.; Rufo, J.; Severo, M.; Ramos, E.; Barros, H.; Fernandes, E.O. Source apportionment of $\mathrm{CO}_{2}, \mathrm{PM}_{10}$ and VOCs levels and health risk assessment in naturally ventilated primary schools in Porto, Portugal. Build. Environ. 2016, 96, 198-205. [CrossRef]

35. Yu, C.W.F.; Kim, J.T. Building pathology, investigation of sick buildings-VOC Emissions. Indoor Built Environ. 2011, 19, 30-39. [CrossRef]

36. Yu, C.W.F.; Kim, J.T. Long-term impact of formaldehyde and VOC emissions from wood-based products on indoor environments; and issues with recycled products. Indoor Built Environ. 2011, 19, 1-13. [CrossRef]

37. Gong, Y.; Wei, Y.; Cheng, J.; Jiang, T.; Chen, L.; Xu, B. Health risk assessment and personal exposure to Volatile Organic Compounds (VOCs) in metro carriages-A case study in Shanghai, China. Sci. Total Environ. 2017, 574, 1432-1438. [CrossRef] [PubMed]

38. Fang, G.T.; Xie, J.C.; Ji, Y.B. Investigation and analysis of formaldehyde, acetaldehyde and total volatile organic compounds in indoor air of five cities in China. Environ. Chem. 2015, 34, 1215-1217.

39. Tang, X.; Bai, Y.; Duong, A.; Smith, M.; Li, L.; Zhang, L. Formaldehyde in China: Production, consumption, exposure levels, and health effects. Environ. Int. 2009, 35, 1210-1224. [CrossRef] [PubMed]

40. Kim, H.; Lim, Y.; Shim, D.; Shon, J.; Yang, J. Risk assessment of Volatile Organic Compounds (VOCs) and formaldehyde in Korean public facilities: Derivation of health protection criteria levels. Asian J. Atmos. Environ. 2011, 5, 121-133. [CrossRef] 
41. Liang, B.S.; Tian, R.S. Development of indoor air quality evaluation standard for total volatile organic compounds (TVOC). Chongqing Environ. Sci. 2003, 25, 1-4.

42. Morrison, G.C.; Nazaroff, W.M. Ozone interactions with carpet secondary emissions of aldehydes. Environ. Sci. Technol. 2002, 36, 2185-2192. [CrossRef] [PubMed]

43. Poppendieck, D.G.; Hubbard, H.F.; Weschler, C.J.; Corsi, R.L. Formation and emissions of carbonyls during and following gas-phase ozonation of indoor materials. Atmos. Environ. 2007, 41, 7614-7626. [CrossRef]

44. Fjällström, P.; Andersson, B.; Nilsson, C. Drying of linseed oil paints: The effects of substrate on the emission of aldehyde. Indoor Air 2003, 13, 277-282. [CrossRef] [PubMed]

45. Chi, X.; Shi, Y.Q.; Yan, J.; Fu, C.; Zhang, B. Dynamic change of formaldehyde concentration in indoor air after newly decorated in Wuhan. J. Environ. Health 2007, 24, 81-83.

(C) 2017 by the authors. Licensee MDPI, Basel, Switzerland. This article is an open access article distributed under the terms and conditions of the Creative Commons Attribution (CC BY) license (http:/ / creativecommons.org/licenses/by/4.0/). 